\title{
Construction Strategies for Multiscale Personality Inventories
}

\author{
Matthias Burisch \\ University of Hamburg
}

In a replication of the well-known Goldberg (1972) study, sets of inventory scales were constructed from a common item pool, using variants of what are here called the Inductive, Deductive, and External strategies, respectively. Two additional scales were also written. Peer ratings for 21 traits, employing two different scale formats, served as criteria. Subjects were 138 students of both sexes. In spite of a number of procedural differences, most notably a concentration on "traitrelevant" criteria and the use of zero-order correlations as indices of validity, Goldberg's main finding stood unchallenged: Very little variation in validity was attributable to construction strategies. It is pointed out, however, that the Deductive strategy accomplishes its feats with much less effort and considerably shorter scales. Further work with this methodology is urged, as is increased attention to the measurement of criterion variables.

That validity coefficients of approximately $r$ $=.30$ are not altogether atypical for personality scales is not a new finding. Judging from the public embarrassment, however, that followed Mischel's (1968) provocative book, one might infer collective repression of this information on the part of many. While the ensuing discussion concentrated on the issues of "consistency of personality" and problems of validation research (e.g., Alker, 1972; Bem, 1972), there was

APPLIED PSYCHOLOGICAL MEASUREMENT

Vol. 2, No. 1 Winter 1978 pp. 97-111

(c) Copyright 1978 West Publishing Co. hardly any mention of another suspicionnamely, that something might be wrong with the way personality inventories are usually constructed.

But there were some (e.g., Fiske, 1971) who questioned the prevalent beliefs that a good inventory had to be:

1. global at the conceptual level (Peterson, 1965);

2. heterogeneous and "disguised" in item content (e.g., Cattell \& Tsujioka, 1964); and

3. developed either by means of some elaborate multivariate technique, preferably factor analysis, or by the "empirical" criterion-group approach (e.g., Meehl, 1945).

And the evidence was not all that negative. By methods that laid maximum stress on clearly defined constructs and content saturation of items, Jackson $(1967,1970)$ had achieved median validity coefficients of approximately $r=.50$ for his 22-scale Personality Research Form, using peer ratings as criteria. Though still not satisfactory compared to absolute standards, these figures were encouraging, indeed.

What could be expected from modifying construction strategies? Clearly, this is an empirical question; but systematic studies were painfully wanting. 


\section{The Goldberg Study}

The important studies of Goldberg and his associates (Hase \& Goldberg, 1967; Goldberg, 1972) were undertaken to fill this gap. Only the roughest outline can be presented here; and the comparison of multivariate prediction techniques, contained in the monograph by Goldberg (1972), will be omitted completely.

Using various strategies or sub-strategies, 5 sets of 11 scales each were (or had been) constructed from the common 468-item pool of the California Psychological Inventory (CPI). Four additional "control" sets (e.g., random scales) will be neglected here.

The analyses in Goldberg (1972) used the data from 152 female students living together in one dormitory. In addition to the CPI protocols from which all scales were scored, 13 criterion variables were measured for each subject. These ranged from mean peer ratings for five traits (such as "dominance") to a measure of "academic survival" (one, two, or three years spent in college).

For each of the five 11-scale inventories and each of the 13 criteria, a multiple regression equation was developed, using only one-half of the sample. The resulting equation was then cross-validated on the other half. Repeating the process in the reverse direction yielded two cross-validity coefficients. These were averaged to furnish a validity index for each particular inventory-criterion combination.

The most outstanding result was obtained when the validity coefficients were again averaged across the 13 criteria: not only was the general level very low (grand mean of .26), but the range was only from .24 to .28 . This finding-that all of the strategies produced inventories with almost identical validities-should have surprised many, whose expectations, it must be admitted, may have varied. Those favoring the "content" approach might find some comfort in Goldberg's result that a 5-scale subset of his "Rational" inventory outdid all other subsets in the study, with a mean cross-validity (averaged over all 13 criteria) of $r=.39$.
The Goldberg study must be regarded as a milestone in the history of personality assessment. Nonetheless, it is open to criticisms which limit generalizations from its results, as the author himself concedes in welcome frankness. Since these objections provided part of the motivation behind the present replication, some of them are discussed below.

\section{Criticisms of the Goldberg Study}

Criterion variables. Under what circumstances can a variable $Y$ be called a criterion for a test $X$ ? One informal rule is that $Y$ and $X$ should be measures of the same target construct and that, given conflicting information, any practical decision should be based on $Y$ rather than on $X$. This definition obviously pertains to theory-guided research.

Admittedly, practical necessities often require some complex behavior to be predicted by whatever information happens to be at hand. The differences between these two research contexts should be reflected in terminology: "criteria" can be distinguished from "target variables." The (cross-validated) correlation of a broadbandwidth battery with a target of the latter sort might then be termed its "effectiveness" rather than its "validity."

From this point of view almost all but the six peer ratings (five traits plus "how well known") seem to fall into the "target" category. To expect that the scales constructed to measure 11 of Murray's (1938) "needs" should predict the time a student will drop out of college may be asking a little too much. If one inventory excels another with respect to "effectiveness," that may be because it contains more pertinent scales-not necessarily better ones. And, if several inventories yield equally unsatisfactory predictions, one might surmise that most of their target variables were equally out of reach.

Validity coefficients. A related objection can be raised against the use of multiple correlations as validity coefficients. If the sociability scale in an inventory does not correlate with a peer rating of sociability, while scales for dominance 
and "intellectual efficiency" do, the multiple correlation between the whole set and the rating can be quite high. Should it then be claimed that "validity" has been demonstrated? In fact, as Tables 6 and 7 in Hase and Goldberg (1967) show, some criteria were most highly correlated with the "wrong" predictors.

Construction of inventory scales. It would be unfair to judge the scales in a study of this type by the most taxing of standards. On the other hand, a comparison of strategies is meaningful only insofar as each of them is given a chance to "do its best." The Theoretical and the Rational inventories, variants of what Goldberg calls the "Intuitive" strategy, would not be expected to operate at their upper bound of quality. Of the 11 Rational scales, 7 were compiled by just one author; the rest were standard CPI scales. For both sets the implicit definitions of the concepts to be measured were apparently very broad. The construct of "Social Presence" was represented by no less than 56 items, almost one-eighth of the total pool. The item "I like to listen to symphony orchestra concerts on the radio" was scored for "Academic Achievement." The item analysis eliminated only items correlating below .19 with their own scale; correlations with other scales were not inspected. In fact, even item overlap among the scales was tolerated.

The Theoretical scales included items which at least two of three graduate students agreed were relevant for one of 11 Murray needs. No empirical data were used in the process. Both facts may account for the item consistency $\left(r_{i i}\right)$ coefficients (Hase \& Goldberg, 1967, Table 1), which could have been higher for such relatively short scales.

Sample effects. Goldberg admits that the degree of optimization differed among the various inventories. The Factor and Multiple Scalogram Analysis inventories were constructed from practically the same set of data as that used for validation purposes. Thus, there was hardly a chance for these scales to come "unglued" internally. In contrast, the Empirical and Rational inventories were developed from dif- ferent samples; and the Theoretical inventory was constructed data-free.

If one accepts the above criticisms of criterion variables and construction methodology and neglects the problem of validity coefficients for the moment-since no analyses of discriminant validity were published-then the Theoretical inventory seems to deserve the prize. Regarding only the six peer ratings as criteria, mean crossvalidated correlations were Theoretical $.40, \mathrm{Ra}$ tional .38, Factor .38, Empirical .30, and Multiple Scalogram Analysis .28.

While it is true that the Rational and Factor sets are close runners-up, a global comparison should take into consideration the fact that the Theoretical inventory not only had the second shortest scales, but also was constructed with a minimum of effort. On the basis of just this one study, test constructors would probably opt for one of the "Intuitive" strategies.

It might be speculated that an even clearer contrast would have emerged had the latter strategies not been handicapped in what is potentially their strongest point-unfortunately by a necessary feature of the design. With the content approach, the first step is a precise definition of the concept to be measured (see Jackson. 1971). Subsequently, there is an attempt to formulate items that "hit the core" of the construct; thus, the term "deductive" is preferred for the strategy. In the reverse process, that of selecting items which seem to "fit" a particular concept (or even to cluster items first and label them later), there is always the temptation to accept too many items, thereby making the scale "fuzzy." However, granted that the item pool had to be the same for all strategies, this problem could not be circumvented.

In view of the above considerations, a replication seemed worthwhile-if only to investigate the matter in a different cultural setting.

\section{Inventory Scales}

\section{Method}

The Freiburger Persönlichkeitsinventar (FPI, Fahrenberg \& Selg, 1970; Fahrenberg, Selg, \& 
Hampel, 1973) provided both the common item pool for this study and a set of scales representing the "Internal" strategy of scale construction (which is here called "Inductive"). Although content for its 212 items was borrowed from such sources as the MMPI, MPI, EPI, and 16 PF questionnaires, the FPI is one of the few inventories that was not simply translated into German. Of its 12 standard scales, 9 were formed (with some exceptions) according to the highest absolute item loading in a principal components analysis, using the test protocols of 630 subjects. Only the first 8 of these scales (hereinafter referred to as STD scales) were included in this project. (STD 9 has the function of a lie scale, while STD 10 Extraversion, STD 11 Neuroticism, and STD 12 Masculinity are superordinate scales constructed by quasi-rational or external methods, respectively.)

Quite a few items apparently have little to do with the names of their scales. For example, the items "I feel almost constantly hungry" and "I used to dream rather often" appear in STD 2 Aggressiveness. As a matter of fact, in this study roughly one quarter of all items correlated highest with some STD scale other than its own. Although derived from an orthogonal factor rotation, several scales intercorrelate substantially (maximum $r=.61$ ).

In an attempt to approximate the Deductive strategy, the author and three students of psychology independently searched the FPI for trait constructs that seemed to be represented in its items. In one case an STD concept (Excitability) could be carried over, while others were more specific subconstructs (e.g., Offensiveness as the spontaneous variety of Aggressiveness). Still others were unique (e.g., Daydreaming). Working definitions were set up for 10 variables that appeared promising. Next, each team member independently collected items that (for him/her) conformed to the trait definition. Items were either included in a provisional scale or rejected only after intensive group discussions.

FPI protocols of 186 tirst-term psychology students provided the data base for an item analysis. Items correlating higher with an alien scale than with their own (so-called "anomalies") were discarded and not reused for other scales. (Four anomalous items were retained because of their content; of these only two remained anomalous in the main sample.)

Those eight Deductive scales that showed the best internal properties-high KR20 $\left(r_{u}\right)$, Loevinger's homogeneity coefficient $\left(H_{t}\right)$, mean item-scale correlation, and low correlations of items with alien scales-were kept for the final inventory, abbreviated DED. As with the STD scales, there was no item overlap. After exclusion of 35 items during item analysis, 74 remained.

In terms of the above internal properties and with respect to scale correlations, even the ad hoc provisional scales equalled or surpassed the much more elaborately constructed STD scales. (The one exception was the KR20 coefficient, which heavily depends on test length. This coefficient is reported in spite of its well-known disadvantages, e.g., Loevinger (1947) and Lumsden (1976), chiefly because the custom is so deeply rooted.)

The last-minute decision to write two additional Deductive scales was prompted by the discovery that a second questionnaire, to be given for other purposes, did not quite fill its two pages in print. An ostensibly easy-to-measure construct (Spontaneous Aggression) and an ostensibly hard one (Depressive Mood) were chosen, and in about two hours seven items were written for the first (scale $A^{\prime}$ ) and five items for the second (scale $D^{\prime}$ ). No further editing was possible, nor could any quantitative analyses be undertaken at the time.

To see how an inductive grouping method would fare with the 74 items selected for inventory DED, these were subjected to a principal components analysis, using the same data as for the item analyses. An effort was made to imitate the steps taken for the construction of the standard FPI: phi coefficients were used and five factors, accounting for $32 \%$ of the variance, were extracted and rotated by varimax. Items were 
assigned to factors according to highest absolute loading, again with a few exceptions. Factor scales were labeled in the customary impressionistic fashion. The resulting inventory was abbreviated FAC.

A set of External scales (abbreviated EXT) was constructed after collection of the validation data. For this purpose, items were selected which correlated maximally with the mean peer ratings that served as the primary criteria. It was decided to match the length of parallel External and STD or DED scales sharing the same criterion rating. Thus, since scale STD 1 Somatic Lability had 34 items, those 34 items out of the total pool most valid for the Somatic Lability rating were picked to form scale EXT-S1. The same procedure was followed for the rest of the STD scales and for DED 1 through DED 8. Two corresponding versions were developed for each scale, one from one-half of the sample which was validated in the other, and vice-versa. This made up a total of 32 External scales, many of them overlapping, of course. The $2 \times 8$ scales aiming at STD ratings were designated EXT-S, while the $2 \times 8$ scales paralleling DED comprised subinventory EXT-D.

\section{Criterion Variables}

As the best compromise solution to the criterion problem, trait ratings by close acquaintances were chosen. Self-ratings were also obtained.

Two rating scale formats were employed. One was the familiar horizontal 9-point ("unanchored") scale, as shown in Figure 1.

In an attempt to reduce the much-criticized ambiguity of such ratings, example-anchored scales were painstakingly constructed after the methods of Taylor et al. $(1970,1972)$. These were vertical 100-point scales anchored by 8 to 12 statements illustrating various degrees of the trait in question. For instance, a rating of 91 on an aggressiveness scale was illustrated by the phrase "Sometimes enjoys tormenting others," while "Gets into arguments very rarely" was printed next to point 31 . The statements paraphrased content appearing in the corresponding inventory scales. Their positions on the rating scales were obtained from a rank-order scaling (cf. Taylor, 1968).

\section{Subjects}

Subjects were 78 male and 60 female students of the University of Hamburg, excluding psychology students. They were contacted in their dormitories and offered a small amount of money in addition to feedback of their test results if they participated. Each subject was required to find two friends who knew him or her well and were willing to act as raters. Raters were paid the same sum of money.

Group testing sessions of about 60 to 90 minutes in duration were held in the dormitories. Subjects anonymously filled in the FPI and a second questionnaire containing scales $\mathrm{A}^{\prime}$ and $D^{\prime}$, interspersed with other items. They then rated themselves on the same scales that were used for the peer ratings.

Concurrently, but in separate rooms, the criterion raters received a booklet containing 21 unanchored and 21 example-anchored scales, together with written instructions.

The entire procedure was repeated after two weeks. Raters of the same subject worked inde-

\section{Figure 1}

\section{Example of Unanchored Rating Scale}

\section{Aggressiveness}

$\begin{array}{llllllllllllll}\begin{array}{l}\text { aggressive } \\ \text { inconsiderate } \\ \text { offensive }\end{array} & 9 & 8 & 7 & 6 & 5 & 4 & 3 & 2 & 1 & \begin{array}{l}\text { unaggressive } \\ \text { considerate } \\ \text { peacable }\end{array}\end{array}$


pendently during each session. Coordination of the various data sets was accomplished by means of code numbers.

\section{Analyses}

The principal method of analysis consisted of intercorrelating all variables in the study. A few special procedures are described below.

Criterion variables. Before computing retest stabilities and correlations for the peer ratings, these were averaged over each ratee's pair of raters. No further transformations of raw data were used.

Inter-rater agreement was appraised by the coefficient $r_{k}^{*}$. This coefficient is a slightly modified variant of the standard coefficient $r_{k}$ (see Winer, 1962, sect. 4.5), yielding an unbiased estimate for the reliability of $k$ raters' average rating, as defined by Equation 1 .

$$
r_{k}^{*}=1-\left(\frac{n-3}{n-1}\right)\left(\frac{M S_{e}}{M S_{b}}\right), \quad(n>3) \text { [1] }
$$

with

$$
M S_{e}=\frac{S s_{b}+S S_{r}}{n(k-1)}
$$

and

$n$ = number of ratees

$k=$ number of raters

$M S_{e}=$ mean square error

$M S_{b}=$ mean square between raters

$S S_{b}=$ sum of squares between raters

$S S_{r}=$ sum of squares for residual

Inventory scales. Internal properties were analyzed in a variety of ways. In addition to familiar coefficients (such as retest stability, internal consistency, and Loevinger's homogeneity coefficient), item consistency and mean itemscale correlation (part-whole corrected biserials) were also computed. The coefficient of item consistency, $r_{i}$, is simply a scale's internal consistency estimated for the fictitious scale length
"1 item" by the Spearman-Brown formula. The number of "anomalies" per scale was also counted, i.e., instances where an item correlated more highly with one or more other scales than with its own.

All figures given for external scales represent averages of coefficients computed separately for the two versions of each scale, using the respective cross-validation half of the data only. Therefore the $N$ in these cases if 69. (By mistake three subjects did not receive scales $\mathrm{A}^{\prime}$ and $\mathrm{D}^{\prime}$, reducing that $N$ to 135 .)

Since all the validities were based on a mixedsex sample, one might wonder to what extent they are comparable to results from studies using subjects of either sex only, e.g., Goldberg's. To control for possible inflation or deflation of coefficients due to sample heterogeneity, sex was partialled out of all validities, using point-biserials for correlations with that variable. The strongest single effect produced in this way was the decrease of a coefficient from .40 to .35 . The mean validity of an inventory was reduced by .02 at most. The same was true for validities of self for peer ratings: mean shrinkage of .01 with unanchored scales and of .01 (first session) or .02 (second session) with example-anchored scales. It seemed justified, therefore, to report only uncorrected correlations computed from the total sample.

\section{Results}

\section{Criterion Variables}

The time-consuming construction of exampleanchored (EA) rating scales (from which considerable improvement had been expected) must be regarded as a failure. In no respect were they appreciably superior to the simple unanchored (UA) scales.

Table 1 contains information on retest stability over the two-week interval $\left(r_{t t}\right)$, inter-rater agreement $\left(r_{k}^{*}\right)$, and intercorrelations of ratings within the same scale format. Figures below the main diagonal of the correlation matrix repre- 


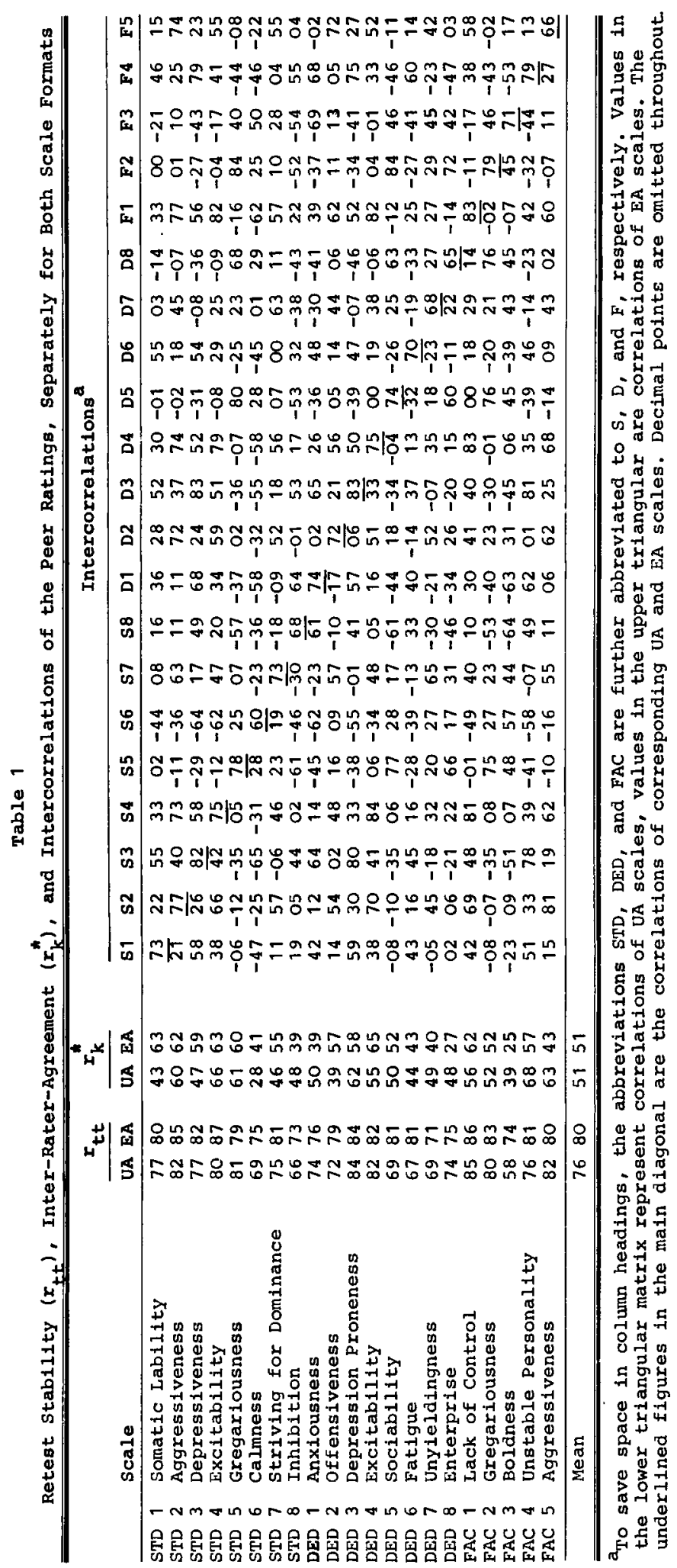


sent UA correlations, while EA intercorrelations are above the main diagonal. Only the results of Session 1 are given, since no marked changes occurred in Session 2.

Although the average stability coefficients were quite adequate, inter-rater agreement was disappointing. This failure to obtain well-defined criterion information may be the chief weakness of the present study. Increasing the number of raters per subject would have raised the size of these coefficients, but it might also have served to reduce the validity of the ratings as more remote acquaintances would have had to be accepted.

The pattern of correlations within the UA and EA scales, respectively, is quite similar and in general makes good sense semantically. Correlations of parallel UA and EA scales (the main diagonal elements) ranged from .60 to .83 , with a mean of .74. Apparently the anchor statements, added on EA scales to clarify trait definitions, did not substantially change raters" interpretations of what should be rated.

There are some hunches as to why the example-anchored scales did not live up to expectations. Single statements were employed as anchors in this study, whereas Taylor et al. (1972) used groups of statements clustering at certain scale positions. The latter approach may introduce confusion when some statements in a cluster apply to a ratee, while others do not. But it may also help to convey images of personality "types" which can serve as reference points for the raters. With the technique used in the present paper, different anchor statements, sometimes far apart on a scale, often seemed equally applicable. In addition, item content was reflected in the statements, in order to guarantee the same degree of "fairness" to all inventories and strategies. This resulted in sets of statements covering a wide spectrum of behavior at very different levels of abstraction.

More research is needed to identify the crucial factors. Training raters prior to obtaining their judgments would also appear promising where it is technically possible. One lesson from these re- sults is that methods of criterion measurement deserve much more attention than they normally receive in validity studies.

\section{Inventory Scales}

Internal properties. Table 2 lists some basic information for the 21 scales of the Standard (STD), Deductive (DED), and Factor (FAC) inventories, as well as for scales $A^{\prime}$ and $D^{\prime}$ and the 16 scales of the External (EXT) inventory.

Column NI gives the number of items per scale. STD (and EXT-S) had the longest scales and DED (and EXT-D) had the shortest. Note that the scale lengths of inventories STD and EXT-S and of inventories DED and EXT-D were matched. In spite of wide variations in scale length, mean retest stabilities, listed in column $r_{t t}$, ranged only from a low of .82 (EXTD) to a high of .88 (EXT-S). Mean internal consistency (KR20) was much more affected, varying from .62 and .64 (EXT-D) to .80 and .83 (STD). Controlling for the effects of scale length (coefficient $r_{i i}$ ) brought DED to the top and sent EXT-S to the bottom of the rank order. The $r_{i t}$ values reflect the somewhat higher specificity of the DED scales; so does Loevinger's homogeneity coefficient $H_{r}$. A similar pattern was found for mean item-scale correlations, presented in the next two columns under the heading $r_{i t}$. Finally, in the "Anom." columns are the numbers of items anomalously correlating more highly with at least one other scale than with their own. More than one-quarter of the STD items fell into this category, as compared to less than $15 \%$ of the DED and FAC items. (With 8 DED and 5 FAC scales, chance probabilities are unequal.) Because of large item overlap, anomalies were not counted for EXT scales.

In summary, wherever the "sameness" of the items in a scale was the quality to be assessed, the DED scales were generally best, followed closely by the FAC inventory. In contrast, the EXT and STD scales, and particularly the subset EXT-D, proved to be more heterogeneous statistically. As with the validity coefficients, 
Table 2

Internal Properties of All Inventory Scales, Separately for sessions 1 and 2 a

\begin{tabular}{|c|c|c|c|c|c|c|c|c|c|c|c|c|c|}
\hline \multirow{2}{*}{\multicolumn{2}{|c|}{$\frac{}{\operatorname{con} s}$}} & \multirow{2}{*}{ scale } & \multirow[b]{2}{*}{$\mathrm{NI}$} & \multirow[b]{2}{*}{$r_{t t}$} & \multicolumn{2}{|c|}{$\mathrm{KR} 2 \mathrm{O}$} & \multicolumn{2}{|c|}{$r_{i i}$} & \multicolumn{2}{|c|}{$\mathrm{H}_{t}$} & \multicolumn{2}{|c|}{$\bar{r}_{i t}$} & Anom. \\
\hline & & & & & 1 & 2 & & 2 & 1 & 2 & & 2 & 2 \\
\hline $\begin{array}{l}\text { STD } \\
\text { STD } \\
\text { STD } \\
\text { STD } \\
\text { STD } \\
\text { STD } \\
\text { STD } \\
\text { STD }\end{array}$ & $\begin{array}{l}1 \\
2 \\
3 \\
4 \\
5 \\
6 \\
7 \\
8\end{array}$ & $\begin{array}{l}\text { Somatic Lability } \\
\text { Aggressiveness } \\
\text { Depressiveness } \\
\text { Excitability } \\
\text { Gregariousness } \\
\text { Calmness } \\
\text { Striving for Dominance } \\
\text { Inhibition }\end{array}$ & $\begin{array}{l}34 \\
26 \\
28 \\
20 \\
28 \\
20 \\
20 \\
20\end{array}$ & $\begin{array}{l}87 \\
82 \\
91 \\
87 \\
92 \\
89 \\
76 \\
87 \\
\end{array}$ & $\begin{array}{l}84 \\
67 \\
87 \\
86 \\
88 \\
82 \\
64 \\
83\end{array}$ & $\begin{array}{l}90 \\
70 \\
92 \\
87 \\
89 \\
84 \\
66 \\
86\end{array}$ & $\begin{array}{l}13 \\
07 \\
20 \\
23 \\
20 \\
19 \\
08 \\
20\end{array}$ & $\begin{array}{l}21 \\
08 \\
28 \\
25 \\
23 \\
21 \\
09 \\
24\end{array}$ & $\begin{array}{l}19 \\
12 \\
27 \\
33 \\
30 \\
26 \\
12 \\
27\end{array}$ & $\begin{array}{l}30 \\
13 \\
37 \\
35 \\
33 \\
29 \\
13 \\
33\end{array}$ & $\begin{array}{l}47 \\
31 \\
55 \\
62 \\
57 \\
53 \\
34 \\
52\end{array}$ & $\begin{array}{l}62 \\
36 \\
67 \\
64 \\
62 \\
56 \\
37 \\
59\end{array}$ & $\begin{array}{rr}8 & 3 \\
14 & 15 \\
4 & 2 \\
4 & 3 \\
5 & 2 \\
7 & 9 \\
11 & 11 \\
6 & 7 \\
\end{array}$ \\
\hline STD & & Mean & 50 & 87 & 80 & 83 & 16 & 20 & 23 & 28 & 49 & 57 & $30827 \%$ \\
\hline $\begin{array}{l}\text { DED } \\
\text { DED } \\
\text { DED } \\
\text { DED } \\
\text { DED } \\
\text { DED } \\
\text { DED } \\
\text { DED }\end{array}$ & $\begin{array}{l}1 \\
2 \\
3 \\
4 \\
5 \\
6 \\
7 \\
8\end{array}$ & $\begin{array}{l}\text { Anxiousness } \\
\text { offensiveness } \\
\text { Depression Proneness } \\
\text { Excitability } \\
\text { Sociability } \\
\text { Fatigue } \\
\text { Unyieldingness } \\
\text { Enterprise }\end{array}$ & $\begin{array}{r}13 \\
11 \\
10 \\
11 \\
12 \\
5 \\
6 \\
6\end{array}$ & $\begin{array}{l}87 \\
75 \\
85 \\
87 \\
90 \\
80 \\
72 \\
80 \\
\end{array}$ & $\begin{array}{l}80 \\
56 \\
81 \\
85 \\
82 \\
60 \\
55 \\
60 \\
\end{array}$ & $\begin{array}{l}84 \\
67 \\
83 \\
85 \\
86 \\
68 \\
59 \\
59 \\
\end{array}$ & $\begin{array}{l}23 \\
11 \\
30 \\
33 \\
28 \\
23 \\
17 \\
20 \\
\end{array}$ & $\begin{array}{l}29 \\
16 \\
33 \\
34 \\
34 \\
29 \\
20 \\
19\end{array}$ & $\begin{array}{l}30 \\
17 \\
45 \\
49 \\
38 \\
38 \\
32 \\
28 \\
\end{array}$ & $\begin{array}{l}37 \\
25 \\
53 \\
50 \\
45 \\
45 \\
33 \\
27 \\
\end{array}$ & $\begin{array}{l}56 \\
32 \\
65 \\
72 \\
63 \\
50 \\
42 \\
43 \\
\end{array}$ & $\begin{array}{l}64 \\
46 \\
69 \\
75 \\
71 \\
58 \\
47 \\
42 \\
\end{array}$ & $\begin{array}{ll}2 & 3 \\
3 & 2 \\
1 & 1 \\
0 & 0 \\
0 & 0 \\
1 & 2 \\
0 & 1 \\
2 & 2 \\
\end{array}$ \\
\hline DED & & Mean & 25 & 83 & 70 & 74 & 23 & 27 & 35 & 39 & 56 & 63 & 128158 \\
\hline $\begin{array}{l}\text { FAC } \\
\text { FAC } \\
\text { FAC } \\
\text { FAC } \\
\text { FAC } \\
\end{array}$ & $\begin{array}{l}1 \\
2 \\
3 \\
4 \\
5\end{array}$ & $\begin{array}{l}\text { Lack of Control } \\
\text { Gregariousness } \\
\text { Boldness } \\
\text { Unstable Personality } \\
\text { Aggressiveness }\end{array}$ & $\begin{array}{l}15 \\
16 \\
12 \\
18 \\
13\end{array}$ & $\begin{array}{l}88 \\
91 \\
81 \\
90 \\
76\end{array}$ & $\begin{array}{l}82 \\
84 \\
75 \\
84 \\
59 \\
\end{array}$ & $\begin{array}{l}83 \\
87 \\
79 \\
89 \\
68\end{array}$ & $\begin{array}{l}23 \\
25 \\
20 \\
22 \\
10\end{array}$ & $\begin{array}{l}25 \\
29 \\
23 \\
30 \\
14\end{array}$ & $\begin{array}{l}37 \\
35 \\
29 \\
32 \\
16\end{array}$ & $\begin{array}{l}39 \\
40 \\
34 \\
44 \\
22 \\
\end{array}$ & $\begin{array}{l}62 \\
60 \\
51 \\
57 \\
37\end{array}$ & $\begin{array}{l}65 \\
67 \\
58 \\
69 \\
43 \\
\end{array}$ & $\begin{array}{l}1 \\
1 \\
3 \\
3 \\
3 \\
\end{array}$ \\
\hline FAC & & Mean & 80 & 86 & 77 & 81 & 20 & 24 & 30 & 36 & 54 & 62 & $15811 \%$ \\
\hline $\begin{array}{l}\text { EXT- } \\
\text { EXT- } \\
\text { EXT- } \\
\text { EXT- } \\
\text { EXT- } \\
\text { EXT- } \\
\text { EXT- } \\
\text { EXT- }\end{array}$ & $\begin{array}{l}-S 1 \\
-S 2 \\
-S 3 \\
-S 4 \\
-S 5 \\
-S 6 \\
-S 7 \\
-S 8\end{array}$ & $\begin{array}{l}\text { Somatic Lability } \\
\text { Aggressiveness } \\
\text { Depressiveness } \\
\text { Excitability } \\
\text { Gregariousness } \\
\text { Calmness } \\
\text { Striving for Dominance } \\
\text { Inhibition }\end{array}$ & $\begin{array}{l}34 \\
26 \\
28 \\
20 \\
28 \\
20 \\
20 \\
20\end{array}$ & $\begin{array}{l}92 \\
82 \\
91 \\
84 \\
91 \\
89 \\
77 \\
92 \\
\end{array}$ & $\begin{array}{l}88 \\
73 \\
88 \\
83 \\
82 \\
87 \\
49 \\
81\end{array}$ & $\begin{array}{l}91 \\
72 \\
90 \\
83 \\
85 \\
87 \\
52 \\
82\end{array}$ & $\begin{array}{l}18 \\
10 \\
21 \\
21 \\
14 \\
26 \\
06 \\
17\end{array}$ & $\begin{array}{l}23 \\
09 \\
23 \\
22 \\
18 \\
25 \\
05 \\
19\end{array}$ & $\begin{array}{l}27 \\
14 \\
30 \\
30 \\
20 \\
35 \\
08 \\
24\end{array}$ & $\begin{array}{l}34 \\
14 \\
34 \\
31 \\
25 \\
35 \\
08 \\
27\end{array}$ & $\begin{array}{l}54 \\
40 \\
59 \\
58 \\
50 \\
63 \\
23 \\
51\end{array}$ & $\begin{array}{l}63 \\
39 \\
62 \\
59 \\
56 \\
64 \\
23 \\
56\end{array}$ & \\
\hline EXT- & & Mean & 50 & 88 & 79 & 80 & 16 & 18 & 23 & 26 & 50 & 53 & \\
\hline $\begin{array}{l}\text { EXT- } \\
\text { EXT- } \\
\text { EXT- } \\
\text { EXT- } \\
\text { EXT- } \\
\text { EXT- } \\
\text { EXT- } \\
\text { EXT- }\end{array}$ & $\begin{array}{l}-D 1 \\
-D 2 \\
-D 3 \\
-D 4 \\
-D 5 \\
-D 6 \\
-D 7 \\
-D 8\end{array}$ & $\begin{array}{l}\text { Anxiousness } \\
\text { Offensiveness } \\
\text { Depression Proneness } \\
\text { Excitability } \\
\text { Sociability } \\
\text { Fatigue } \\
\text { Unyieldingness } \\
\text { Enterprise }\end{array}$ & $\begin{array}{r}13 \\
11 \\
10 \\
11 \\
12 \\
5 \\
6 \\
6 \\
\end{array}$ & $\begin{array}{l}89 \\
74 \\
84 \\
82 \\
89 \\
81 \\
76 \\
77 \\
\end{array}$ & $\begin{array}{l}78 \\
35 \\
81 \\
77 \\
72 \\
52 \\
58 \\
47\end{array}$ & $\begin{array}{l}80 \\
32 \\
81 \\
79 \\
77 \\
61 \\
55 \\
50\end{array}$ & $\begin{array}{l}21 \\
06 \\
29 \\
26 \\
19 \\
19 \\
19 \\
13 \\
\end{array}$ & $\begin{array}{l}23 \\
05 \\
29 \\
28 \\
22 \\
24 \\
18 \\
16 \\
\end{array}$ & $\begin{array}{l}29 \\
09 \\
41 \\
35 \\
24 \\
23 \\
24 \\
19 \\
\end{array}$ & $\begin{array}{l}31 \\
08 \\
42 \\
36 \\
31 \\
32 \\
24 \\
23\end{array}$ & $\begin{array}{l}55 \\
20 \\
66 \\
61 \\
51 \\
40 \\
41 \\
33 \\
\end{array}$ & $\begin{array}{l}58 \\
17 \\
67 \\
63 \\
57 \\
48 \\
40 \\
40\end{array}$ & \\
\hline EXT- & & Mean & .25 & 82 & 62 & 64 & 19 & 21 & 25 & 28 & 47 & 50 & \\
\hline $\begin{array}{l}A^{\prime} \\
D^{\prime}\end{array}$ & & $\begin{array}{l}\text { Spontaneous Aggression } \\
\text { Depressive Mood }\end{array}$ & $\begin{array}{l}7 \\
5 \\
\end{array}$ & $\begin{array}{l}75 \\
73 \\
\end{array}$ & $\begin{array}{l}61 \\
60 \\
\end{array}$ & $\begin{array}{l}64 \\
55 \\
\end{array}$ & $\begin{array}{l}19 \\
23 \\
\end{array}$ & $\begin{array}{l}20 \\
20 \\
\end{array}$ & $\begin{array}{l}37 \\
67 \\
\end{array}$ & $\begin{array}{l}40 \\
52 \\
\end{array}$ & $\begin{array}{l}38 \\
39 \\
\end{array}$ & $\begin{array}{l}44 \\
43 \\
\end{array}$ & \\
\hline
\end{tabular}

$a_{F o r} S T D, D E D$, and FAC $N=138$; for EXT $N=138$; for $A^{\prime}$ and $D^{\prime} N=135$. See text for explanations. Scales EXT-S1 through EXT-S8 share the same criterion rating (and length) with scales STD 1 through STD 8; so do scales EXT-D1 through EXT-D8 with scales DED 1 through DED 8. Anomalies were not counted for the EXT scales which overlap mutually. 
there are no appropriate tests of significance, since just one sample was used. Moreover, all inventories overlap mutually. From a practical standpoint, however, the similarities are far more impressive than the differences.

Somewhat clearer contrasts emerge when within-inventory correlations are compared. Mean absolute intercorrelations of scales were: STD .36; DED .24; FAC .26; EST-S .67; EXT-D .43. The higher level of independence among the DED and the FAC scales cannot be attributed to their lower reliability. Double correction for attenuation, using retest stabilities, gave these average figures: STD .42; DED .30; FAC .31. Disattenuated correlations could not be averaged for the heavily overlapping EXT scales since quite a few of them exceeded 1.0 in absolute value.

Validity. Correlations of all inventory scales with corresponding peer ratings are presented in Table 3, separately for both rating scale formats and both testing sessions. Mean coefficients, averaged over both formats and sessions. are given in the column "PR $\bar{r}$." Number of items is repeated in the "NI" column.

There were no special rating scales for $\mathrm{A}^{\prime}$ and $D^{\prime}$. It seemed appropriate, however, to use the ratings of Aggressiveness (STD 2), Offensiveness (DED 2), and Aggressiveness (FAC 5) as targets for $A^{\prime}$ and those of Depressiveness (STD 3), Depression Proneness (DED 3), and Unstable Personality (FAC 4) for $\mathrm{D}^{\prime}$.

The righthand column of Table 3 ("OL \%") gives the percentage of overlapping items included in both versions of an EXT scale. The two EXT-S1 scales, for instance, had 12 items $(35.3 \%)$ in common. Because there was no within-inventory overlap among the scales of STD, $\mathrm{DED}$, and FAC, the figures there are zero.

Looking at these results in summary fashion, there is mostly support for the null hypothesis. For inventories STD, DED, and FAC, mean validity coefficients of $.39, .39$, and .41 render tests of significance unnecessary. The scales of EXT-S were slightly better than their STD counterparts; EXT-D, with scales equally as short as
DED, was less valid. The most plausible interpretation of this divergency is in terms of item overlap. In choosing items for EXT-D, a higher degree of selectivity was possible because fewer items were needed. But in a new sample these items regressed more markedly towards the mean. Upon cross-validation, they were typically not among the most valid ones. In fact, with the 6-item scales of EXT-D7 and EXT-D8, there was no overlap at all.

Particularly gratifying, of course, was the performance of scales $\mathrm{A}^{\prime}$ and $\mathrm{D}^{\prime}$. Although by far the shortest in their respective content areas, $A^{\prime}$ clearly performed best of all "aggression" scales, while $\mathrm{D}^{\prime}$ reached the same level as the other "depression" scales.

Some additional findings cast further doubt on the traditional wisdom concerning test length and validity. In a few cases, DED or FAC scales were almost or fully contained within longer STD scales. For example, DED 5 and DED 6 are subsets of STD 5 and STD 1, respectively. The validities of the longer and the shorter scales proved to be practically undistinguishable. The mean correlation of STD 1 (34 items) with STD 1 peer ratings was .40 , but DED $6(5$ items) achieved almost the same value (.38). DED 6 peer ratings correlated .34 with both DED 6 and STD 1. This was typical for all such comparisons.

While one important aspect of test quality is discriminant validity, there is no standard procedure to appraise it. To obtain a rough index, incidences were counted where an inventory scale possessed an equal or higher correlation with some "alien" peer rating scale than with its target. The proportion of such "stray" cases to the maximum possible number was $18 \%$ for STD, $11 \%$ for DED, $8 \%$ for FAC, $24 \%$ for EXT$\mathrm{S}$, and $18 \%$ for EXT-D. Although none of these figures is entirely satisfactory-taking into account the often small distance between "right" and second best "wrong" validities-inventory EXT-S appears least acceptable on these grounds. This is explained mainly by the heavy overlap among different scales within the same 
Table 3

Validities of Inventory Scales for Peer Ratings (PR) on Unanchored (UA) and Example-Anchored (EA) Rating Scales, Separately for Sessions 1 and $2^{a}$

\begin{tabular}{|c|c|c|c|c|c|c|c|c|c|}
\hline & & \multirow[b]{2}{*}{ Scale } & \multirow[b]{2}{*}{$\mathrm{NI}$} & \multicolumn{2}{|c|}{$\mathrm{UA}$} & \multicolumn{2}{|c|}{ E'A } & \multicolumn{2}{|l|}{$\mathrm{PR}$} \\
\hline & & & & 1 & 2 & 1 & 2 & $\overline{\mathbf{r}}$ & OL 8 \\
\hline $\begin{array}{l}\text { STD } \\
\text { STD } \\
\text { STD } \\
\text { STD } \\
\text { STD } \\
\text { STD } \\
\text { STD } \\
\text { STD } \\
\end{array}$ & $\begin{array}{l}1 \\
2 \\
3 \\
4 \\
5 \\
6 \\
7 \\
8\end{array}$ & $\begin{array}{l}\text { Somatic Lability } \\
\text { Aggressiveness } \\
\text { Depressiveness } \\
\text { Excitability } \\
\text { Gregariousness } \\
\text { Calmness } \\
\text { Striving for Dominance } \\
\text { Inhibition }\end{array}$ & $\begin{array}{l}34 \\
26 \\
28 \\
20 \\
28 \\
20 \\
20 \\
20\end{array}$ & $\begin{array}{l}43 \\
17 \\
46 \\
51 \\
51 \\
29 \\
26 \\
38 \\
\end{array}$ & $\begin{array}{l}40 \\
13 \\
50 \\
44 \\
54 \\
49 \\
20 \\
38 \\
\end{array}$ & $\begin{array}{l}40 \\
23 \\
42 \\
55 \\
45 \\
42 \\
27 \\
31\end{array}$ & $\begin{array}{l}37 \\
17 \\
48 \\
52 \\
57 \\
45 \\
24 \\
39\end{array}$ & $\begin{array}{l}40 \\
18 \\
47 \\
51 \\
52 \\
42 \\
24 \\
37\end{array}$ & $\begin{array}{l}0.0 \\
0.0 \\
0.0 \\
0.0 \\
0.0 \\
0.0 \\
0.0 \\
0.0\end{array}$ \\
\hline STD & & Mean & 24.50 & 38 & 39 & 39 & 41 & 39 & 0.0 \\
\hline $\begin{array}{l}\text { DED } \\
\text { DED } \\
\text { DED } \\
\text { DED } \\
\text { DED } \\
\text { DED } \\
\text { DED } \\
\text { DED }\end{array}$ & $\begin{array}{l}1 \\
2 \\
3 \\
4 \\
5 \\
6 \\
7 \\
8\end{array}$ & $\begin{array}{l}\text { Anxiousness } \\
\text { Offensiveness } \\
\text { Depression Proneness } \\
\text { Excitability } \\
\text { Sociability } \\
\text { Fatigue } \\
\text { Unyieldingness } \\
\text { Enterprise }\end{array}$ & $\begin{array}{r}13 \\
11 \\
10 \\
11 \\
12 \\
5 \\
6 \\
6 \\
\end{array}$ & $\begin{array}{l}30 \\
14 \\
54 \\
53 \\
52 \\
34 \\
23 \\
38 \\
\end{array}$ & $\begin{array}{l}49 \\
18 \\
44 \\
48 \\
46 \\
34 \\
31 \\
37\end{array}$ & $\begin{array}{l}37 \\
29 \\
48 \\
49 \\
44 \\
35 \\
25 \\
38\end{array}$ & $\begin{array}{l}45 \\
16 \\
45 \\
50 \\
52 \\
32 \\
31 \\
39\end{array}$ & $\begin{array}{l}41 \\
19 \\
48 \\
50 \\
49 \\
34 \\
28 \\
38\end{array}$ & $\begin{array}{l}0.0 \\
0.0 \\
0.0 \\
0.0 \\
0.0 \\
0.0 \\
0.0 \\
0.0\end{array}$ \\
\hline DED & & Mean & 9.25 & 38 & 39 & 38 & 39 & 39 & 0.0 \\
\hline $\begin{array}{l}\text { FAC } \\
\text { FAC } \\
\text { FAC } \\
\text { FAC } \\
\text { FAC }\end{array}$ & $\begin{array}{l}1 \\
2 \\
3 \\
4 \\
5\end{array}$ & $\begin{array}{l}\text { Lack of Control } \\
\text { Gregariousness } \\
\text { Boldness } \\
\text { Unstable Personality } \\
\text { Aggressiveness }\end{array}$ & $\begin{array}{l}15 \\
16 \\
12 \\
18 \\
13\end{array}$ & $\begin{array}{l}55 \\
44 \\
38 \\
53 \\
12 \\
\end{array}$ & $\begin{array}{l}45 \\
39 \\
36 \\
51 \\
22 \\
\end{array}$ & $\begin{array}{l}57 \\
52 \\
33 \\
47 \\
23\end{array}$ & $\begin{array}{l}43 \\
52 \\
48 \\
42 \\
25\end{array}$ & $\begin{array}{l}50 \\
47 \\
39 \\
48 \\
21 \\
\end{array}$ & $\begin{array}{l}0.0 \\
0.0 \\
0.0 \\
0.0 \\
0.0\end{array}$ \\
\hline FAC & & Mean & 14.80 & 41 & 39 & 43 & 42 & 41 & 0.0 \\
\hline $\begin{array}{l}\text { EXT- } \\
\text { EXT- } \\
\text { EXT- } \\
\text { EXT- } \\
\text { EXT- } \\
\text { EXT- } \\
\text { EXT- } \\
\text { EXT- }\end{array}$ & $\begin{array}{l}-S 1 \\
-S 2 \\
-S 3 \\
-S 4 \\
-S 5 \\
-S 6 \\
-S 7 \\
-S 8 \\
\end{array}$ & $\begin{array}{l}\text { Somatic Lability } \\
\text { Aggressiveness } \\
\text { Depressiveness } \\
\text { Excitability } \\
\text { Gregariousness } \\
\text { Calmness } \\
\text { Striving for Dominance } \\
\text { Inhibition }\end{array}$ & $\begin{array}{l}34 \\
26 \\
28 \\
20 \\
28 \\
20 \\
20 \\
20\end{array}$ & $\begin{array}{l}44 \\
38 \\
51 \\
48 \\
52 \\
32 \\
36 \\
46\end{array}$ & $\begin{array}{l}48 \\
30 \\
49 \\
43 \\
49 \\
51 \\
34 \\
46 \\
\end{array}$ & $\begin{array}{l}42 \\
42 \\
47 \\
50 \\
40 \\
47 \\
24 \\
43 \\
\end{array}$ & $\begin{array}{l}42 \\
31 \\
48 \\
50 \\
53 \\
41 \\
34 \\
47 \\
\end{array}$ & $\begin{array}{l}44 \\
35 \\
49 \\
48 \\
49 \\
43 \\
32 \\
46 \\
\end{array}$ & $\begin{array}{l}35.3 \\
26.9 \\
25.0 \\
45.0 \\
42.9 \\
30.0 \\
20.0 \\
25.0\end{array}$ \\
\hline $\mathrm{EXT}-$ & & Mean & 24.50 & 43 & 44 & 42 & 43 & 43 & 31.3 \\
\hline $\begin{array}{l}\text { EXT-I } \\
\text { EXT-I } \\
\text { EXT-I } \\
\text { EXT-I } \\
\text { EXT-I } \\
\text { EXT-1 } \\
\text { EXT-I } \\
\text { EXT-I }\end{array}$ & $\begin{array}{l}-D 1 \\
-D 2 \\
-D 3 \\
-D 4 \\
-D 5 \\
-D 6 \\
-D 7 \\
-D 8\end{array}$ & $\begin{array}{l}\text { Anxiousness } \\
\text { offensiveness } \\
\text { Depression Proneness } \\
\text { Excitability } \\
\text { Sociability } \\
\text { Fatigue } \\
\text { Unyieldingness } \\
\text { Enterprise }\end{array}$ & $\begin{array}{r}13 \\
11 \\
10 \\
11 \\
12 \\
5 \\
6 \\
6 \\
\end{array}$ & $\begin{array}{l}28 \\
23 \\
50 \\
53 \\
43 \\
33 \\
18 \\
36\end{array}$ & $\begin{array}{l}37 \\
37 \\
40 \\
49 \\
39 \\
37 \\
19 \\
36\end{array}$ & $\begin{array}{l}32 \\
34 \\
45 \\
48 \\
39 \\
31 \\
08 \\
25 \\
\end{array}$ & $\begin{array}{l}39 \\
34 \\
42 \\
53 \\
46 \\
32 \\
20 \\
34 \\
\end{array}$ & $\begin{array}{l}34 \\
32 \\
44 \\
51 \\
42 \\
33 \\
16 \\
33 \\
\end{array}$ & $\begin{array}{r}7.7 \\
18.2 \\
30.0 \\
45.5 \\
33.3 \\
20.0 \\
0.0 \\
0.0 \\
\end{array}$ \\
\hline EXT-1 & & Mean & 9.25 & 36 & 37 & 33 & 38 & 36 & 19.3 \\
\hline$A^{\prime}$ & & Spontaneous Aggression & 7 & $\begin{array}{l}45 \\
34 \\
42\end{array}$ & $\begin{array}{l}52 \\
49 \\
53\end{array}$ & $\begin{array}{l}44 \\
43 \\
39\end{array}$ & $\begin{array}{l}52 \\
49 \\
45\end{array}$ & 45 & 0.0 \\
\hline$D^{\prime}$ & & Depressive Mood & 5 & $\begin{array}{l}51 \\
55 \\
45\end{array}$ & $\begin{array}{l}47 \\
49 \\
51\end{array}$ & $\begin{array}{l}47 \\
52 \\
46\end{array}$ & $\begin{array}{l}44 \\
47 \\
46\end{array}$ & 48 & 0.0 \\
\hline
\end{tabular}

a see footnote Table 2 and text for explanations. 
sub-inventory version; there were some intercorrelations beyond .90 . This, in turn, may partly be due to the comparatively small item pool of the FPI; a few items were among the most valid for many criteria.

A final remark concerns the correlations of inventory scales with corresponding self-ratings. Reflecting largely the similarity between the test constructor's explicit and the subjects' implicit conceptualizations of a trait, these coefficients may be viewed as measures of "face validity." Mean correlations averaged across scales, scale formats, and sessions were: STD .58, DED .60, FAC .62, EXT-S .59, EXT-D .55. These figures corroborate the findings as to validity. The good showing of the EXT scales is even more remarkable here because they contained many remote items with little or no manifest relationship to scale labels. No explanation can be offered, but the phenomenon will be studied further.

\section{Self-Ratings}

To compare the usefulness of direct self-ratings against the more elaborate inventory scales, subjects had also been asked to judge themselves, using the same scales as had been used for the peer ratings. Table 4 presents their retest stabilities $\left(r_{t}\right)$ and validities for peer ratings $\left(r_{s p}\right)$ separately for both scale formats and both sessions.

The average stability was comparatively low here-one coefficient was even below .50-but these self-ratings took only a fraction of the time required by most of the inventory scales. Again, there was no advantage whatsoever for either scale format.

Peer ratings were predicted slightly better by direct self-ratings than by inventory scales, as was also found by several previous investigators, e.g., Carroll (1952); Wetzel (1963; cf. Peterson, 1965); Hase \& Goldberg (1967); Norman (1969). This effect is not altogether surprising, since there must be interdependencies between the image held by a person's peers and his or her self-image; if both are measured by identical in- struments, "nuisance effects" due to different operationalizations of a trait are minimized. In view of the simplicity and economy of rating scales, however, the question can be raised, "Why continue to construct inventories if selfratings do a better job more inexpensively?" (cf. also Taylor et al., 1972).

There is no hard and fast answer to this question. To the author's knowledge, the superiority of self-ratings has only been demonstrated in research with anonymous subjects. In real-life settings, such as a psychiatric clinic, the outcome might be different. Admittedly, any verbal assessment technique is susceptible to impression management. Laymen's ratings must be more or less restricted to "folk concepts," which may be the most meaningful ones, anyway. Trait labels may convey even more disparate denotations in representative samples of subjects than items do; and there may be difficulties with subjects low on verbal comprehension, but both these hunches may turn out wrong. Thus, in the absence of reliable evidence, it would seem wisest to push both lines of research.

\section{Discussion}

In spite of the best of intentions, there are a number of weak points that limit interpretations in much the same way as was pointed out for the Goldberg study. Most notable is the use of insufficiently focused criterion ratings. Two factors that could not be adequately controlled are similarity between the derivation and the validation samples and the size of the former. The greatest amount of data went into the construction of STD, but these subjects were probably not fully comparable with the student groups. The opposite is true for DED and FAC, and even more so for EXT. The two random halves of the main sample can be expected to be the most similar pair of subsamples; nevertheless, an $N$ of only 69 may not permit stable correlation estimates.

The external strategy was also handicapped by a limited item pool; however, so was the de- 
Table 4

Analyses of the Self Ratings: Retest Stability ( $\left.r_{t t}\right)$ and Correlations with Corresponding Peer Ratings ( $r_{s p}$ ), Separately for Both Scale Formats and Sessions. $\quad N=138$

\begin{tabular}{|c|c|c|c|c|c|c|c|c|}
\hline & & & \multicolumn{2}{|c|}{$r_{t t}$} & \multicolumn{4}{|c|}{$r_{s p}$} \\
\hline & & & \multirow[b]{2}{*}{ UA } & \multirow[b]{2}{*}{ EA } & \multicolumn{2}{|c|}{ UA } & \multicolumn{2}{|c|}{ EA } \\
\hline & & & & & 1 & 2 & 1 & 2 \\
\hline STD & 1 & Somatic Lability & 76 & 84 & 50 & 54 & 47 & 44 \\
\hline STD & 2 & Aggressiveness & 65 & 69 & 44 & 32 & 43 & 36 \\
\hline STD & 3 & Depressiveness & 76 & 76 & 49 & 54 & 37 & 47 \\
\hline STD & 4 & Excitability & 64 & 76 & 47 & 40 & 53 & 52 \\
\hline STD & 5 & Gregariousness & 83 & 76 & 47 & 52 & 47 & 53 \\
\hline STD & 6 & Calmness & 65 & 68 & 31 & 43 & 30 & 33 \\
\hline STD & 7 & Striving for Dominance & 66 & 54 & 42 & 31 & 34 & 34 \\
\hline STD & 8 & Inhibition & 64 & 67 & 35 & 36 & 43 & 50 \\
\hline DED & 1 & Anxiousness & 77 & 66 & 39 & 46 & 43 & 43 \\
\hline DED & 2 & Offensiveness & 68 & 58 & 40 & 39 & 25 & 19 \\
\hline DED & 3 & Depression Proneness & 77 & 75 & 52 & 50 & 53 & 53 \\
\hline DE'D & 4 & Excitability & 69 & 58 & 56 & 57 & 52 & 47 \\
\hline DED & 5 & Sociability & 78 & 79 & 56 & 45 & 41 & 51 \\
\hline DED & 6 & Fatigue & 74 & 77 & 41 & 42 & 31 & 34 \\
\hline DED & 7 & Unyieldingness & 56 & 60 & 19 & 31 & 33 & 26 \\
\hline DED & 8 & Enterprise & 77 & 75 & 41 & 35 & 39 & 31 \\
\hline FAC & 1 & Lack of Control & 69 & 74 & 56 & 50 & 52 & 49 \\
\hline FAC & 2 & Gregariousness & 68 & 77 & 44 & 38 & 42 & 50 \\
\hline FAC & 3 & Boldness & 47 & 64 & 43 & 41 & 32 & 41 \\
\hline FAC & 4 & Unstable Personality & 81 & 76 & 48 & 55 & 46 & 47 \\
\hline \multirow[t]{2}{*}{ FAC } & 5 & Aggressiveness & 68 & 60 & 45 & 41 & 36 & 29 \\
\hline & & Mean & 71 & 71 & 44 & 44 & 41 & 42 \\
\hline
\end{tabular}

ductive construction. The good showing of inventories DED and FAC, which used precisely the same items in somewhat different arrangements, lends some support to the notion that it is the intrinsic qualities of an item (e.g., comprehensibility, subjective relevance to subjects) that count, rather than its assignment to the "correct" construct. However, there will be limits to this rule.
Considering the points above and the many procedural differences, the replication of Goldberg's main results is remarkably clear: no dramatic strategy effects when a common item pool is used. Equally well substantiated and representing even more of the facts is a somewhat different formulation: With "economy-class" criteria, typical validity coefficients of inductively- or externally-constructed inventories can 
be achieved by much simpler deductive methods and considerably shorter scales. This is in line with the recent findings of Ashton and Goldberg (1973) and Jackson (1975), employing relatively inexperienced students as item writers.

The next task, then, should be to aim at some real advancements, using more serious criteria and optimization of the deductive methodology.

\section{References}

Alker, H. A. Is personality situationally specific or intrapsychically consistent? Journal of Personality. 1972, 40, 1-16.

Ashton, S. G., \& Goidberg, L. R. In response to Jackson's challenge: The comparative validity of personality scales constructed by the external (empirical) strategy and scales developed intuitively by experts, novices, and laymen. Journal of Research in Personality, 1973, 7, 1-20.

Bem, D. J. Constructing cross-situational consistencies in behavior: Some thoughts on Alker's critique of Mischel. Journal of Personality, 1972. $40,17-26$.

Carroll, J. B. Ratings on traits measured by a factored personality inventory. Journal of Abnormal and Social Psychology, 1952, 47, 626-632.

Cattell, R. B., \& Tsujioka, B. H. The importance of factor-trueness and validity, versus homogeneity and orthogonality, in test scales. Educational and Psychological Measurement, 1964, 24,3-30.

Fahrenberg, J., \& Selg, H. Das Freiburger Persönlichkeitsinventar. Göttingen: Hogrefe, 1970.

Fahrenberg, J., Selg, H., \& Hampel, R. Das Freiburger Persönlichkeitsinventar (2nd ed.). Göttingen: Hogrefe, 1973.

Fiske, D. W. Measuring the Concepts of Personality. Chicago: Aldine, 1971.

Goldberg, L. R. Parameters of personality inventory construction and utilization: A comparison of prediction strategies and tactics. Multivariate Behavioral Research Monographs, 1972, No. 72-2.

Hase, H. D., \& Goldberg, L. R. Comparative validity of different strategies of constructing personality inventory scales. Psychological Bulletin, 1967,67, 231-248.

Jackson, D. N. Personality Research Form Manual. Goshen, NY: Research Psychologists Press, 1967.

Jackson, D. N. A sequential system for personality scale development. In C. D. Spielberger (Ed.), Current Topics in Clinical and Community Psychology (Vol. 2). New York: Academic Press, 1970.
Jackson, D. N. The dynamics of structured personality tests: 1971. Psychological Review, 1971, 78, 229-248.

Jackson, D. N. The relative validity of scales prepared by naive item writers and those based on empirical methods of personality scale construction. Educational and Psychological Measurement, 1975, 35. 361-370.

Loevinger, J. A systematic approach to the construction and evaluation of tests of ability. Psychological Monographs, 1947, 61 (Whole no. 285).

Lumsden, J. Test theory. Annual Review of Psychology, 1976, 27, 251-280.

Meehl, P. E. The dynamics of "structured" personality tests. Journal of Clinical Psychology, 1945, 1. 296-303.

Mischei, W. Personality and Assessment. New York: Wiley, 1968.

Murray, H. A. Explorations in Personality. Cambridge: Harvard University Press, 1938.

Norman, W. T. "To see oursels as ithers see us!": Relations among self-perceptions, peer-perceptions and expected peer-perceptions of personality attributes. Multivariate Behavioral Research, 1969, 4. 417-443.

Peterson, D. R. Scope and generality of verbally defined personality factors. Psychological Review, $1965,72.48-59$.

Taylor, J. B. A brief ranking method as an alternative to Thurstone scaling procedures. Perceptual and Motor Skills, 1968, 26, 533-534.

Taylor, J. B., Haefele, E., Thompson, P., \& O'Donoghue, C. The reliability of example-anchored scales under conditions of rater heterogeneity and divergent behavior sampling. Educational and Psychological Measurement, 1970, 30. 301-310.

Taylor, J. B., Ptacek, M., Carithers, M., Griffin, C., \& Coyne, L. Rating scales as measures of clinical judgment. III: Judgments of the self on personality inventory scales and direct ratings. Educational and Psychological Measurement, 1972, 32, 543-557.

Wetzel, L. C. Personality traits and cognitive meanings. Master's thesis, University of Illinois, 1963.

Winer, B. J. Statistical Principles in Experimental Design. New York: McGraw-Hill, 1962.

\section{Acknowledgements}

Most data analyses for this project were carried out at the University of Hamburg Computer Center. The author is indebted to Ansa Burisch. Ingrid Harbeck. Barbara Hochdörfer, Barbara Knauf. Ute Oster- 
walder, Barbara Rindermann, and Renate Rudolph. who cooperated at various stages of the investigation. Special thanks are due Lewis $R$. Goldberg, upon whose groundwork this study builds. His stimulation, encouragement, and good advice is gratefully acknowledged - which certainly does not im ply his responsibility for the final product.

\section{Author's Address}

Matthias Burisch, Universität Hamburg, Psychologisches Institut II, von-Melle-Park 5, Hamburg 13, Germany. 